recent migration, the old religion of the images was blended into, and perpetuated by, the more recent culture.

The conclusions of Mrs. Scoresby Routledge have been extended by a second paper in the same issue of Folk-lore by Mr. Henry Balfour on the ethnological affinities of the natives of Easter Island. $\mathrm{He}$ arrives at the conclusion that the island culture is composite, and exhibits traces of fusion of at least two stocks. The first was a Melanesian migration, which introduced the practice of distending the ear-lobe, a characteristic style in art, certain special types of stone implements, and the cult of the frigate-bird, which was designed as a magical method of increasing the food supply. This Melanesian culture was submerged by a wave of Polynesian immigrants, to whom is due a new bird cult, aiming at increasing in a like magical way the supply of birds and eggs. This culture seems to be closely allied to that of the Solomon Islands, and "it seems likely that the symbolism of many of the ideographic signs employed in the Easter Island script may be explained by a study on the spot of closely similar designs still used in the Solomon Islands, the symbolic significance of which might be ascertained before it is too late." Thus a survey of the materials collected by $\mathrm{Mr}$. and Mrs. Scoresby Routledge, interpreted by the wide ethnographical knowledge of Mr. Henry Balfour, seems to bring us at last within reach of a solution of the mystery of Easter Island. It may be hoped that the clues suggested by him will be followed by some careful local anthropologist.

\section{SCIENTIFIC ACTIVITIES OF THE SMITHSONIAN INSTITUTION.}

THE report of the secretary of the Smithsonian Institution for the year ending June 30 , I917, has been received from Washington. It reviews the affairs of the institution, summarises briefly the operations of its several branches, and, in addition, contains, in the form of appendices, detailed reports by the assistantsecretary and others directly in charge of its various activities.

The permanent fund of the institution now amounts to 200,00ol., the limit authorised by Congress. The income during the year under review reached $17,730 l$, and with the cash balance from the previous year the total resources for the financial year amounted to $26,672 l$. The disbursements for the same period were $24,830 l$.

The former secretary of the institution, the late Prof. S. P. Langley, demonstrated in 1896 the feasibility of mechanical flight by a machine heavier than the air propelled by its own power. As an indication of America's debt to his researches, his name is fittingly preserved in the name "Langley Field," a tract of some 1800 acres near Hampton, Va., where important experiments in aviation are now being carried on. The large machine with which Prof. Langley experimented in 1903 proved its worth and its capability of flight during the year reviewed by the report. The institution has established a research laboratory at Langley Field for scientific investigations, and among several sub-committees engaged in the study of aeronautic problems may be mentioned those on aerial mail service, aero torpedoes, aircraft communicating, airplane mapping, the relation of the atmosphere to aeronautics, and the construction and navigation of aircraft.

The usual activities of the institution were continued during the year in carrying out one of its fundamental objects, the increase of knowledge. Various explorations and researches were inaugurated or participated NO. 253 I, VOL. IOI in by the institution, covering the different divisions of astronomical, anthropological, biological, and geological science; but the secretary points out that opportunities for undertaking important lines of investigation are constantly being lost through lack of means to carry them into execution. Moreover, several proposed expeditions to various parts of the world have been delayed temporarily by the war.

The report directs attention again to the work of the Research Corporation, organised in 1912, and having as its officers men particularly interested in the development of industry. The principal income of the corporation is derived from royalties for the use of the Cottrell process for the electrical precipitation of suspended particles. Dr. F. G. Cottrell, the inventor of the process, offered his patents to the Smithsonian, Institution, but as it was impracticable for the institution to administer them commercially, the Research Corporation was organised for that purpose. The corporation seeks to do for industry what other institutions are doing for science, for medicine, and for the improvement of social conditions. An annual fellowship has been established "open to general competition for the purpose of encouraging and assisting men of science in the prosecution of their investigations." To the successful competitor the corporation offers an honorarium of $500 l$, and the assistance of the corporation in securing the most favourable opportunity for prosecuting the particular object of study.

The additions to the libraries of the institution and its branches during the year numbered more than 9000 volumes and pamphlets. Among important gifts were a first consignment of $56 \mathrm{r}$ volumes and 293 pamphlets, part of the botanical library of Dr. J. D Smith, of Baltimore, and the scientific library of Dr. E. A. Mearns, an American zoologist who died in I9I6.

With the secretary's report for I9I7 may be noticed conveniently the annual report of the Board of Regents of the Smithsonian Institution for the year ending June 30 , I916, which has now come to hand. This handsome and well-illustrated volume of 608 pages includes the secretary's report for 1916, to which we directed attention last year; but its most attractive feature is the comprehensive general appendix, with its invaluable selection of miscellaneous scientific memoirs intended for the use of correspondents of the institution, teachers, and other workers engaged in the promotion of knowledge. Among the memoirs are original contributions, translations from foreign periodicals, and reprints from scientific serial publications printed in English.

The original contributions include papers by Prof. C. G. Abbot, director of the Astrophysical Observatory of the institution, on news from the stars; Prof. Paul Bartsch, curator of marine invertebrates in the U.S. National Museum, on pirates of the deep-stories of the squid and octopus; Prof. Albert Mann, on the economic importance of the diatoms; Mr. W. E. Safford, economic botanist to the U.S. Department of Agriculture, on narcotic plants and stimulants of the ancient Americans; Dr. J. W. Fewkes, on a prehistoric Mesa Verde Pueblo and its people; and Mr. Van H. Manning, on mine safety devices developed by the United States Bureau of Mines.

The translations include an address by Prof. A. Pictet, professor of chemistry at the University of Geneva, on molecular structure and life, published in the Revue Scientifique and the author's "Extrait des Archives des Sciences physiques et naturelles, Geneva, I9I5"; a lecture delivered in German in I9I4 in Vienna by Prof. F. Berwerth, on the origin of meteorites; and a lecture given in French by Prof. M. Caullery, exchange professor at Harvard University in I9I6, on the present state of the problem of evolution. 